\title{
Prescribed contraceptives among woman after release from prison
}

\author{
Georgina Sutherland ${ }^{1 *}$, Megan Carroll ${ }^{1}$, Nick Lennox ${ }^{2}$ and Stuart Kinner ${ }^{1,2,3,4}$
}

\begin{abstract}
Background: Despite the high rates of unintended and complicated pregnancy among women who have spent time in prison, little is known about their use of prescribed contraceptives post-prison release. We used a routinely-collected medicine utilisation dataset linked to a longitudinal cohort of adults released from prison to describe the dispensing of contraceptive medication.
\end{abstract}

Findings: The socio-demographic profiles of women in the cohort were characteristic of justice-involved populations: they were young, poorly educated, unemployed prior to incarceration, with a very high proportion identifying as Indigenous. Dispensing claims data showed that in the six months (180 days) after release from prison contraceptive medication had been dispensed to only 19 women (7.6\%).

Conclusion: Our findings raise important questions about the reproductive health needs of women in prison and after their release. This requires urgent research and policy attention with a particular focus on the potential benefits of attending to women's sexual and reproductive health care needs in prison in preparation for return to the community.

Keywords: Contraception; Women; Prisoners; Post-release; Record linkage

\section{Background}

Women, in particular Indigenous women, are the fastest growing sector of the prison population in Australia (Australian Bureau of Statistics 2012). Other developed countries have noted similar rises in rates of female incarcerations (Kong and AuCoin 2008; Ministry of Justice 2012). Typically, women in the criminal justice system experience short durations of imprisonment with high rates of re-offending (Hocking et al. 2002). As a result, there has been a concomitant rise in the number of female prisoners being released back into the community. The post-release period is known to be challenging for all prisoners because of multiple and complex unmet physical, social and mental health needs (Australian Institute of Health and Welfare 2012; Cutcher et al. 2014). For women there are added complexities that relate to their pathways to prison. Previous studies have noted that exposure to childhood and adult sexual abuse, intimate partner violence and alcohol and illicit

\footnotetext{
* Correspondence: georgina.sutherland@unimelb.edu.au

${ }^{1}$ Melbourne School of Population and Global Health, University of Melbourne, Melbourne, VIC, Australia

Full list of author information is available at the end of the article
}

substance use put prison-involved women at greater risk of poor sexual and reproductive health outcomes including sexually transmitted infection (STI) and unintended pregnancy (Clarke et al. 2006a; Martin et al. 2012).

According to surveys of reproductive histories conducted in Australian prisons, incarcerated women have a higher number of pregnancies and become first-time mothers at a much younger age than the general birthing population (Butler et al. 2012; Indig et al. 2010; Richters et al. 2008). While there are no accurate data on either intendedness of birth or terminations in Australia, it appears that women in prison experience unintended pregnancy and terminations at substantially higher rates than the general population of child-bearing women (Butler et al. 2010; Quinn 2008). Yet, the high prevalence of sexual health problems in prisoners means most research in the area has focused on methods to reduce STI transmission, mostly conducted within correctional settings. Much less is known about access to forms of birth control other than condoms after release from prison: a time of heightened risk for unplanned and complicated pregnancy.

The adverse health and social consequences of unintended pregnancy for women and children are amply 
documented (Gipson et al. 2008), emphasising how it important it is for women to be able to plan their pregnancies. Several studies have noted that special attention is needed to ensure that the contraceptive needs of vulnerable groups are met while ensuring their choices are made freely and for themselves (Dehlendorf et al. 2010; Gold, 2014). At the national and international level, there is a lack of information about the health and reproductive needs of women post-incarceration. The ability to access contraception and plan pregnancies, as desired, is a fundamental step for women with histories of imprisonment to break the cycle of disadvantage, but a lack of population-specific data hampers efforts to intervene. In this short report, we use routinely-collected medicine utilisation data linked to a longitudinal cohort of adults released from prison to describe the prevalence of prescribed contraceptives for women in the first six months after their release.

\section{Study overview}

Data for this paper were drawn from the Passports study, a randomised controlled trial designed to improve access to health services among adults released from prison in one state of Australia. Baseline data were collected in prison between August 2008 and July 2010 from adults incarcerated in seven correctional facilities in Queensland who were within six weeks of their expected release from prison $(\mathrm{N}=1325)$. Structured baseline interviews were administered by trained research personnel in a private location in prison. Follow up telephone interviews were conducted either in the community or for those re-incarcerated, in prison, at approximately one, three and six months post release. Women were purposively over-sampled $(n=280)$. A more detailed description of the intervention and study can be found elsewhere (Kinner et al. 2013; Kinner et al. 2014).

\section{Measures}

We used the baseline interviews to describe the sociodemographic characteristics and reproductive histories for women in the cohort aged between 18 and 49 years of age. We restricted our analyses to women in this age range to facilitate comparisons with population-level data on child-bearing women in Australia. The baseline survey covered a range of socio-demographic information including age, education, employment history, and relationship status prior to incarceration.

With participant consent, prison medical records were accessed to obtain information on current medication use. From this we extracted information on the use of prescribed contraception while in prison. Women were asked if they were pregnant at the time of the baseline interview.
Data from consenting female participants were linked to their Pharmaceutical Benefits Scheme (PBS) claims data post-prison release via probabilistic data linkage. Prescribed pharmaceuticals dispensed to Australian residents are subsidised through this scheme. We searched PBS claims data for the dispensing of contraceptive medications within 30, 90 and 180 days of release from prison. Prescribed contraceptives listed on the PBS included combined and progestogen-only oral contraceptive pill, progestogen-only sub-dermal implants, progestogen injection (such as Depo-Provera) and the hormonal levonorgestrel intrauterine device (IUD) known in Australia as Mirena.

Ethical clearance for the study was approved by the University of Queensland's Behavioural and Social Sciences Ethical Review Committee and the Queensland Corrective Services Research Committee. Data linkage was approved by the Commonwealth Department of Human Services.

\section{Findings}

Of the total sample of women in the cohort, 93\% $(n=262)$ provided consent for their interview data to be linked to routinely-collected administrative health and medical records, including the PBS. The vast majority of these women $(n=251)$ were aged under 50 at the time of their baseline interview. As can be seen in Table 1, the socio-demographic characteristics of participants were consistent with the known profile of incarcerated women in Australia: they were young, poorly educated, most were unemployed prior to incarceration and onethird identified as being of Aboriginal or Torres Strait Islander descent. The average length of current incarceration was five months $(\mathrm{M}=151$ days; range 18 days to 7 years). Only two women were taking prescribed contraceptives while in prison.

PBS claims data showed that 30 days after release from prison contraceptive medication had been dispensed to

Table 1 Baseline socio-demographic characteristics of women $<50$ years $(n=251)$

\begin{tabular}{ll}
\hline Variable & Percent (n) \\
\hline Age 18-24 & $25.5 \%(64)$ \\
25-49 & $74.5 \%(187)$ \\
Indigenous & $35.5 \%(89)$ \\
$<10$ years formal schooling & $74.5 \%(187)$ \\
Unemployed & $72.1 \%(181)$ \\
Stable relationship & $46.2 \%(116)$ \\
Dependent children & $46.9 \%(115)$ \\
Previous incarceration & $60.5 \%(152)$ \\
History of sexually transmitted infection (STI) & $31.1 \%(78)$ \\
Currently pregnant & $9.5 \%(18)$ \\
Prescribed contraception in prison & $<1 \%(2)$ \\
\hline
\end{tabular}


only five women (2\%). At 90 days, this rate increased to approximately $4 \%(\mathrm{n}=9)$ and by 180 days (six months post release), 19 women (7.6\%) had had contraceptives dispensed through the PBS. Around half of the women $(\mathrm{n}=9)$ with PBS claims data for contraceptive medication were dispensed oral contraceptives (OC). The remainder $(n=10)$ were dispensed one of the long-acting reversible contraceptives (LARC).

The 19 women with records of dispensed contraceptive medication after release from prison had the same median age as all other women in the cohort (range 20-40). We did not perform tests of association between prescribed contraceptives post-prison release and socio-demographic characteristics because of the small cell frequencies, but the proportions suggest no systematic differences between the two groups. The only exception was for Indigenous status, where 17 of the 19 women who were dispensed prescribed contraceptives were non-Indigenous. Of the two women taking $\mathrm{OC}$ in prison, only one had filled a prescription within 180 days of release.

\section{Conclusions}

Our study suggests that woman released from prison have alarmingly low rates of prescribed contraceptive use. In Australia, medication is the most common form of general contraception (Mazza et al. 2012). Although comparable national data are difficult to obtain, other studies using survey methods have found that around $30 \%$ to $40 \%$ of women between the ages of 18 and 49 years use OC (Richters et al. 2003; Australian Bureau of Statistics 1998). Notwithstanding that we cannot distinguish the sub-population within this cohort at risk of unintended pregnancy - those who are sexually active and not planning to become pregnant - by comparison, less than $4 \%$ of women in our cohort were dispensed OC up to six months post-prison release. Even accounting for all other types of prescribed contraceptive medication, rates of use for women in this study are around one-quarter the levels for all other Australian women in the same age bracket. The proportion of Indigenous women who were dispensed contraceptive medication post release was even smaller.

Our results, although limited in scope, add to the existing body of evidence about unmet contraceptive needs among some of the most vulnerable women living in the community. Two previous studies in Australia have shown poor uptake of contraception among women with hepatitis $C$ (Banwell et al. 2003) and women attending drug treatment services (Black et al. 2012). Both these groups share similar profiles to incarcerated women with high rates of unplanned and high risk pregnancies. The study by Banwell et al. (Banwell et al. 2003) described contraceptive use among their cohort of women as 'disturbingly low' with $9 \%$ using OC. Dispensing of contraceptive medication for women in our study was even lower. These results raise important questions about the way reproductive health needs of women are addressed in prison and upon return to the community, but must be viewed in light of several study limitations.

The main set of limitations relates to our method of ascertainment and potential bias towards undercounting the number of women dispensed contraceptives postprison release. First, we were unable to ascertain contraceptives not listed on the PBS, including copper IUDs, the vaginal ring and 'new generation' OC containing drospirenone. While these new formulations are described as being popular in Australia, we were unable to find reliable estimates of use in the community. Given their relative high cost, however, we are confident that in this cohort of disadvantaged women the dispensing of contraceptives that are not subsidised through the PBS does not account for the very low rates we observed. Second, dispensing of LARC is a likely underestimate given our relatively short follow up period. If women had previously been prescribed a LARC, they may not need a replacement for between three and five years, depending on the device. Nevertheless, we would not expect this undercount to substantially affect our overall estimate because the uptake of LARC methods in Australia is low, at only around 6\% in the general population (Black et al. 2013). Third, we were not able to describe birth control methods that do not require a prescription, including condoms, diaphragms or the emergency contraceptive pill. Given the high rates of STI's in this population, women in prison and after release may be encouraged and therefore more likely to use condoms as their main form of contraception. Finally, we may not have captured access to very low cost prescription contraceptives because the PBS, during our period of data collection, did not record the dispensing of medications priced below the copayment.

Our results warrant further urgent research to explore the reasons for what appears to be very low levels of prescribed contraceptives among women after their release from prison. Women may experience multiple barriers to accessing contraception after their release from prison including not being in a position to negotiate use, the effects of alcohol or other drugs, misinformation about options, and lack of power in decision-making (Clarke et al. 2006b; Sufrin et al. 2009). For all these reasons, family planning and the provision of safe, effective and affordable contraception, according to women's needs, should be considered a key component of health care delivered in prisons. Previous research conducted in a correctional facility in the US showed that offering women the chance to initiate birth control in prison (if they wished to do so) substantially improved uptake 
compared to when services were offered post-release only (Clarke et al. 2006b). This is a powerful illustration of the benefits of throughcare: care that spans from incarceration to community. With only two women using a contraceptive medication in prison in our cohort, we were unable to explore this further.

Our data suggest there is a need to improve access to fertility control methods in prison: a unique point of access for many high risk women. In contrast to historical coercive practices that have plagued debate about the provision of contraception to vulnerable women, we propose that prison services can provide women, who are often socioeconomically and medically marginalised when they return to the community, an opportunity to make fully informed and voluntary decisions about when or if they want children or to manage the number and spacing of children.

\section{Competing interests}

The authors have no competing interests.

\section{Authors' contributions}

GS participated in data analysis and interpretation, wrote the initial draft and drafted the full and final version of the manuscript. MC conducted the data analysis, collaborated with GS on data interpretation and contributed to drafting and critical revision of the manuscript. NL contributed to the design of the Passports study and the critical revision of the manuscript. SK conceived the Passports study, received funding for the project, participated in the drafting and critical revision of the manuscript. All authors read and approved the final manuscript.

\section{Acknowledgments}

The authors wish to thank Queensland Corrective Services for assistance with data collection, and Passports study participants for sharing their stories. This study was funded by National Health and Medical Research Council (NHMRC) Strategic Award \#409966 and NHMRC Project Grant \#1002463. SK is funded by NHMRC Career Development Award \#1004765. The views expressed herein are solely those of the authors, and in no way reflect the views or policies of Queensland Corrective Services. We wish to acknowledge the Australian Government Department of Human Services as the source of Pharmaceutical Benefits Scheme (PBS) records.

\section{Author details}

${ }^{1}$ Melbourne School of Population and Global Health, University of Melbourne, Melbourne, VIC, Australia. ${ }^{2}$ School of Medicine, University of Queensland, Brisbane, QLD, Australia. ${ }^{3}$ Murdoch Childrens Research Institute, Melbourne, VIC, Australia. ${ }^{4}$ School of Public Health and Preventive Medicine, Monash University, Melbourne, VIC, Australia.

Received: 30 December 2014 Accepted: 19 March 2015

Published online: 28 April 2015

\section{References}

Australian Bureau of Statistics. (2012). Prisoners in Australia. Canberra: Australian Bureau of Statistics.

Australian Bureau of Statistics. (1998). Australian Social Trends. Canberra: Australian Bureau of Statistics.

Australian Institute of Health and Welfare. (2012). The health of Australia's prisoners 2012. Canberra: Australian Institute of Health and Welfare.

Banwell, C, Bammer, G, Main, N, Gifford, S, \& O'Brien, M. (2003). Disturbingly low levels of contraception among women living with hepatitis $C$. Aust N Z J Public Health, 27(6), 620-626.

Black, K, Bateson, D, \& Harvey, C. (2013). Australian women need increased access to long-acting reversible contraception. Med J Aust, 199(5), 317-318.
Black, K, Stephen, C, Haber, PS, \& Linteris, N. (2012). Unplanned pregnancy and contraceptive use in women attending drug treatment services. Aust N Z J Obstet Gynaecol, 52, 146-150.

Butler, T, Malacova, E, Ritchers, J, Yap, L, Grant, L, Richards, A, Smith, AM, \& Donovan, B. (2013). Sexual behaviour and sexual health of Australian prisoners. Sex Health, 10(1), 64-73.

Butler, T, Richters, J, Yap, L, Papanastasiou, C, Richards, A, Schneider, K, Grant, L, Smith, A, \& Donovan, B. (2010). Sexual health and behaviour of Queensland prisoners: With Queensland and New South Wales comparisons. Perth and Sydney: National Drug Research Institute, Curtin University and School of Public Health and Community Medicine, University of New South Wales.

Clarke, J, Hebert, MR, Rosengard, C, Rose, JS, DaSilva, BA, \& Stein, MD. (2006a). Reproductive health care and family planning needs among incarcerated women. Am J Public Health, 96(5), 834-839.

Clarke, J, Rosengard, C, Rose, JS, Hebert, MR, Peipert, J, \& Stein, MD. (2006b). Improving birth control service utilization by offering services prerelease vs postincarceration. Am J Public Health, 96(5), 840-845.

Cutcher, Z, Degenhardt, L, Alati, R, \& Kinner, S. (2014). Poor health and social outcomes for ex-prisoners with a history of mental disorder: a longitudinal study. Aust N Z J Public Health, 38, 424-429.

Dehlendorf, C, Rodriguez, MI, Levy, K, Borrero, S, \& Steinauer, J. (2010). Disparities in family planning. Am J Obstet Gynecol, 202(3), 214-220.

Gipson, JD, Koening, MA, \& Hindin, MJ. (2008). The effects of unintended pregnancy on infant, child and parental health: a review of literature. Stud Fam Plann, 39(1), 18-38.

Gold, RB. (2014). Guarding against coercion while ensuring access: a delicate balance. Policy Review, 17(3), 8-14.

Hocking, BA, Young, M, Falconer, A, \& O'Rourke, PK. (2002). Queensland women prisoners' health survey. Brisbane: Department of Corrective Services.

Indig, D, Topp, L, Ross, B, Mamoon, H, Border, B, Kumar, S, \& McNamara, M. (2010). 2009 NSW inmate health survey: key findings report. Sydney: Justice Health.

Kinner, S, Lennox, N, Williams, G, Carroll, M, Quinn, B, Boyle, FM, \& Alati, R. (2013). Randomised contolled trial of a service brokerage intervention for ex-prisoners in Australia. Contemp Clin Trials, 36(1), 198-206.

Kinner, S, van Dooren, K, Boyle, FM, Longo, M, \& Lennox, N. (2014). Development of an intervention to increase health service utilisation in ex-prisoners. Health and Justice, 2, 4.

Kong, R, \& AuCoin, K. (2008). Female offenders in Canada. Ottowa: Statistics Canada.

Martin, RE, Buxton, JA, Smith, M, \& Hislop, TG. (2012). The scope of the problem: the health of incarcerated women in BC. BC Medical Journal, 54(10), 502-508.

Mazza, D, Harrison, C, Taft, A, Britt, H, Hobbs, M, Stewart, K, \& Hussainy, S. (2012). Current contraception management in Australian general practice: an analysis of BEACH data. Med J Aust, 197(2), 110-114.

Ministry of Justice. (2012). Statistics on Women and the Criminal Justice System 2011. London: Ministry of Justice.

Quinn, K. (2008). Women and corrections. Melbourne: Women's Health Victoria.

Richters, J, Butler, T, Yap, L, Kirkwood, K, Grant, L, Smith, A, Schneider, K, \& Donovan, B. (2008). Sexual health and behaviour of New South Wales prisoners. Sydney: School of Public Health and Community Medicine, University of New South Wales.

Richters, J, Grulich, AE, de Visser, RO, Smith, AMA, \& Rissel, CE. (2003). Contraceptive practices among a representative sample of women. Aust N Z J Public Health, 27(2), 210-216.

Sufrin, CB, Tulsky, JP, Goldenson, J, Winter, KS, \& Cohan, DL. (2009). Emergency contraception for newly arrested women: evidence for an unrecognised public health opportunity. J Urban Health, 87(2), 244-253. 